\title{
The election process for the Board of Directors of the Metabolomics Society: call for nomination of new board directors
}

\author{
Ute Roessner
}

(C) Springer Science+Business Media New York 2014

It's election time! The International Metabolomics Society (www.metabolomicssociety.org) is a dynamic society, founded in 2004, and with a membership of almost one thousand scientists that is growing year on year. Historically, the primary activity of the Society has been to organize the premiere international conference in metabolomics each year, with alternating venues in North America, Europe and the greater Asia-Pacific region. While organizing this conference remains one of the most important events in the Society's calendar, the Directors have recently put in place a range of other benefits and activities for its Members.

The Society is led and managed by a Board of 13 Directors (http://www.metabolomicssociety.org/board_of_directors), consisting of leading metabolomics researchers from around the world, and which includes the three Officer positions of President, Treasurer and Secretary. The exiting Officers remain as part of the board for 2 further years to ensure a smooth transition of tasks and responsibilities. For operational efficiency, the Board devolves its daily activities across numerous committees and task groups. These include the Website \& Communications Committee, the Publications Committee, a Membership Committee, a Conference \& Training Committee and a Nominations \& Election Committee. These committees typically consist of 3-6 board members. The task groups, such as the International Affiliation Task Group, the Industry Liaison Task Group, the Data Standards Task Group, the Metabolite Identification Task Group and the Society Strategy Task Group, each consist of a few board members and also have non-board participants from the community.

U. Roessner

Metabolomics Australia and Australian Centre for Plant Functional Genomics, School of Botany, The University of Melbourne, 3010 Parkville, VIC, Australia
Each Director commits to a term of 2 years to the board and the society. After that he/she has the option to stand for re-election for a second 2-year term. Around May/June each year the process for election of replacement Directors is initiated. In 2014, four current Directors will have their second term of duty finished and therefore will provide spaces for four new Directors to be elected. In addition, we have three Directors who will finish their first term and may stand for re-election. For the new positions available we are calling on our membership base to nominate outstanding and excited metabolomics research leaders who would be interested and have the time to be fully committed to serve on the Board of Directors of the Society. The Board is interested to have researchers nominated who are active in the metabolomics sciences and also who are keen and motivated to serve on the Board to develop and strengthen the visibility and viability of the Metabolomics Society further. The nominees also should be able to commit sufficient time to be actively involved in typically two of the Board's tasks groups and committees, an average commitment of $\sim 2 \mathrm{~h}$ per week.

The election process is driven and overseen by the Nominations \& Election Committee, which consists of two Board members and two non-board Members who observe the process for transparency. Once the nomination process is finalized the Nominations \& Election Committee will collect information from the nominees including a short biography and a statement of commitment which will be published on the Society's website allowing the membership to select and vote for their preferred nominees. The voting process will finish in August each year. The Nominations \& Election Committee then selects the nominees with the highest number of votes and invites them to become a Director. Beginning on October 1st, the newly elected Board members begin their term of office. 